\title{
Detection of treponemal DNA in the CSF of patients with syphilis and HIV infection using the polymerase chain reaction
}

\author{
P E Hay, J R Clarke, D Taylor-Robinson, D Goldmeier
}

\begin{abstract}
The polymerase chain reaction (PCR) was used to detect Treponema pallidum DNA in the cerebrospinal fluid (CSF) of patients with and without syphilis. The CSF from 10 of 19 patients with positive serological tests for syphilis who were being investigated for late syphilis were treponemal DNA-positive. In contrast, the CSF from only one of 30 patients with no known history of syphilis was DNApositive. CSF from $28 \mathrm{HIV}$-positive patients was also tested. Fourteen of these patients had central nervous system (CNS) disease and seven were DNA-positive, whereas none of the 14 without CNS disease were DNA-positive. Five of the seven DNA-positive patients had a history of syphilis. Such a history in an HIVpositive patient who had CNS disease was predictive of finding treponemal DNA in the CSF. The PCR had a sensitivity of $47 \%$ and a specificity of $93 \%$ for detecting a known history of syphilis and is a potentially useful tool in treponemal diagnosis.
\end{abstract}

\section{Introduction}

There is clinical evidence that the human immunodeficiency virus (HIV) alters the immune response to Treponema pallidum..$^{1-3} T$. pallidum has been demonstrated in immunocompetent patients after treatment for syphilis, ${ }^{4-9}$ but treponemes are more likely to persist in the cerebrospinal fluid (CSF) of patients infected with HIV than in that of patients who are uninfected. ${ }^{10}$ Furthermore, patients infected with HIV who acquire syphilis may be more likely to progress to clinical neurosyphilis, and at an accelerated rate. ${ }^{11-14}$ It is also possible that trepon-

Clinical Research Centre, Harrow, Middlesex

P E Hay, D Taylor-Robinson

Department of Virology

J R Clarke

Department of Genitourinary Medicine, St. Mary's

Hospital Medical School, London, UK

P E Hay, D Taylor-Robinson, D Goldmeier emes contribute to the neurological disease that is assumed to be caused directly by HIV (subacute encephalopathy) or by other opportunistic infections of the central nervous system (CNS).

We have determined already in the laboratory that the polymerase chain reaction (PCR) is a relatively sensitive and highly specific technique for detecting $T$. pallidum DNA. ${ }^{15}$ In the current study we used the PCR in an attempt to detect treponemal DNA in CSF from patients with and without syphilis, and then to determine the frequency with which treponemal DNA was present in CSF from HIV-infected patients with and without disease of the CNS.

Materials and methods

CSF was collected from the following groups of patients.

Group A-Patients with no known history of syphilis and at no obvious risk of contracting HIV infection. Lumbar puncture was performed to exclude non sexually transmitted pathogens.

Group B-Patients with treponemal disease undergoing lumbar puncture to look for evidence of neurosyphilis.

Group C-HIV-positive patients (CDC group 4) undergoing lumbar puncture for an indication other than syphilis. Half of these patients had CNS disease. Those without CNS disease underwent lumbar puncture as part of an investigation of fever or other non-specific symptoms.

The specimens of CSF were stored in liquid nitrogen until tested. The PCR was performed separately with two sets of 21 base primers to detect DNA sequences from the TMPA and 4D genes of $T$. pallidum as described previously. ${ }^{15}$ Forty cycles of amplification were performed. Specimens were recorded as positive only if both DNA sequences were detected. Distilled water was included in every test as a negative control to exclude DNA contamination of the reagents, and all the results were confirmed by Southern blotting with ${ }^{32} \mathrm{P}$-labelled probes. The sensitivity of the PCR was estimated by testing $500 \mu \mathrm{l}$ aliquots of tenfold dilutions of a preparation of Nichols' strain $T$. pallidum, which contained $1.3 \times 10^{8}$ organisms $/ \mathrm{ml}$. The threshold 
for detection was the $10^{-6}$ dilution giving an estimated sensitivity of 65 organisms. In addition the PCR was $100 \%$ specific when used to test human DNA and a battery of organisms that could have caused falsepositive results. ${ }^{15}$

\section{Diagnosis of syphilis}

This was confirmed for patients in group B by positive TPHA and FTA tests on serum, with or without a positive VDRL test, in the absence of a history of previous treatment for syphilis or yaws. Latency was implied by the absence of recent or current symptoms and signs of primary or secondary syphilis. Neurosyphilis was diagnosed in patients with signs compatible with the diagnosis and a positive CSF VDRL test in the absence of blood contamination. Possible neurosyphilis was diagnosed in patients in whom there were abnormalities of the CSF, but a negative VDRL test and no other cause for the abnormalities (such as HIV infection), or if the CSF TPHA or FTA test was positive making it difficult to exclude the diagnosis with certainty.

There were four patients in group $C$ who gave a history of syphilis but had negative serological tests (table 2). In three cases the history was confirmed by reviewing their records. In the remaining case the patient gave a reliable history of treatment with daily injections of penicillin for 15 days.

\section{Definition of CNS disease}

Patients in Group C were defined as having CNS disease if there were confirmed symptoms or signs referable to the CNS, as recorded in table 2 . Nonspecific headache, although frequently the indication for lumbar puncture was not interpreted as indicating CNS disease in the absence of other abnormalities.

\section{Results \\ Group A patients}

CSF from one of 30 patients was positive in the PCR with both sets of primers. The sample was from a neonate born at 27 weeks gestation, who had developed an intraventricular haemorrhage. Serological tests for syphilis in both the infant and mother were negative.

\section{Group $B$ patients}

The results of tests on 19 patients who had undergone lumbar puncture as part of an investigation of late syphilis are shown in table 1 . All patients had a positive serum TPHA and FTA test but only three had a serum VDRL titre greater than $1:>2$. Two patients were found to have neurosyphilis. One of these (patient $M$ ) presented with a headache and had positive serum TPHA and FTA tests, with a serum VDRL titre of $1 / 128$, but no focal neurological signs.
A VDRL test proved positive on undiluted CSF which contained 92 white cells $/ \mathrm{mm}^{3}$, and $1.0 \mathrm{~g}$ protein/l. The headache resolved following treatment with procaine penicillin which was given at a dose of $1.2 \mathrm{MU}$ daily for 15 days. The other patient had a diagnosis of neurosyphilis established on the basis of a positive VDRL test on CSF. Treponemal DNA was detected by the PCR in the CSF of both of these patients.

Two patients had a diagnosis of possible asymptomatic neurosyphilis. The TPHA test on the CSF of one of these was strongly positive and treponemal DNA was detected in the CSF. The other patient had an increased concentration of protein in the CSF with a pleocytosis. However, FTA and VDRL tests on the CSF were negative and treponemal DNA was not detected. It subsequently emerged that he had been treated for asymptomatic neurosyphilis at another hospital nine years previously.

Fourteen of the remaining 15 patients had a diagnosis of latent treponemal infection, seven had CSF that reacted positively in the PCR for treponemal DNA. The possibility of yaws existed in only one of these patients and the PCR proved negative.

Two patients were HIV antibody-positive, both with CDC stage 2 disease. One of these was patient $M$ with neurosyphilis who was treponemal DNA positive. The other patient had been treated for latent syphilis with erythromycin five years previously and had requested reinvestigation for syphilis. His CSF was normal and treponemal DNA was not detected.

Many of the patients in whose CSF treponemal DNA was detected had serum VDRL titres of $1:<2$. Only one patient with latent syphilis had a serum VDRL of $1:>4$. She had been treated for syphilis in 1947 and eventually had been discharged with apparently negative serological tests. However, a serum VDRL titre of $1: 32$ was found following a right cerebral infarct in 1988. Treponemal DNA was not detected in CSF, which was normal except for a slightly elevated protein concentration of $0.5 \mathrm{~g} / 1$. After treatment with penicillin the VDRL remained unchanged and the patient is being investigated for a paraproteinaemia. It is likely that this was a biological false-positive VDRL.

Table 1 Presence of treponemal DNA detected by the PCR in CSF from 19 patients undergoing lumbar puncture to look for evidence of neurosyphilis

\begin{tabular}{lll}
\hline Diagnosis & $P C R$-positive & $P C R$-negative \\
\hline Neurosyphilis & $2^{\star}$ & 0 \\
Possible asymptomatic & 1 & 1 \\
$\quad$ neurosyphilis & 7 & $7 \dagger$ \\
Latent syphilis & 0 & 1 \\
\hline
\end{tabular}

^Includes one HIV-positive patient.

tIncludes 1 HIV-positive patient, previously treated with erythromycin. 
Table 2 Presentation, CSF findings and syphilis history in 28 HIV-positive individuals undergoing lumbar puncture for an indication other than syphilis. FTA and VDRL tests on CSF were negative in all cases

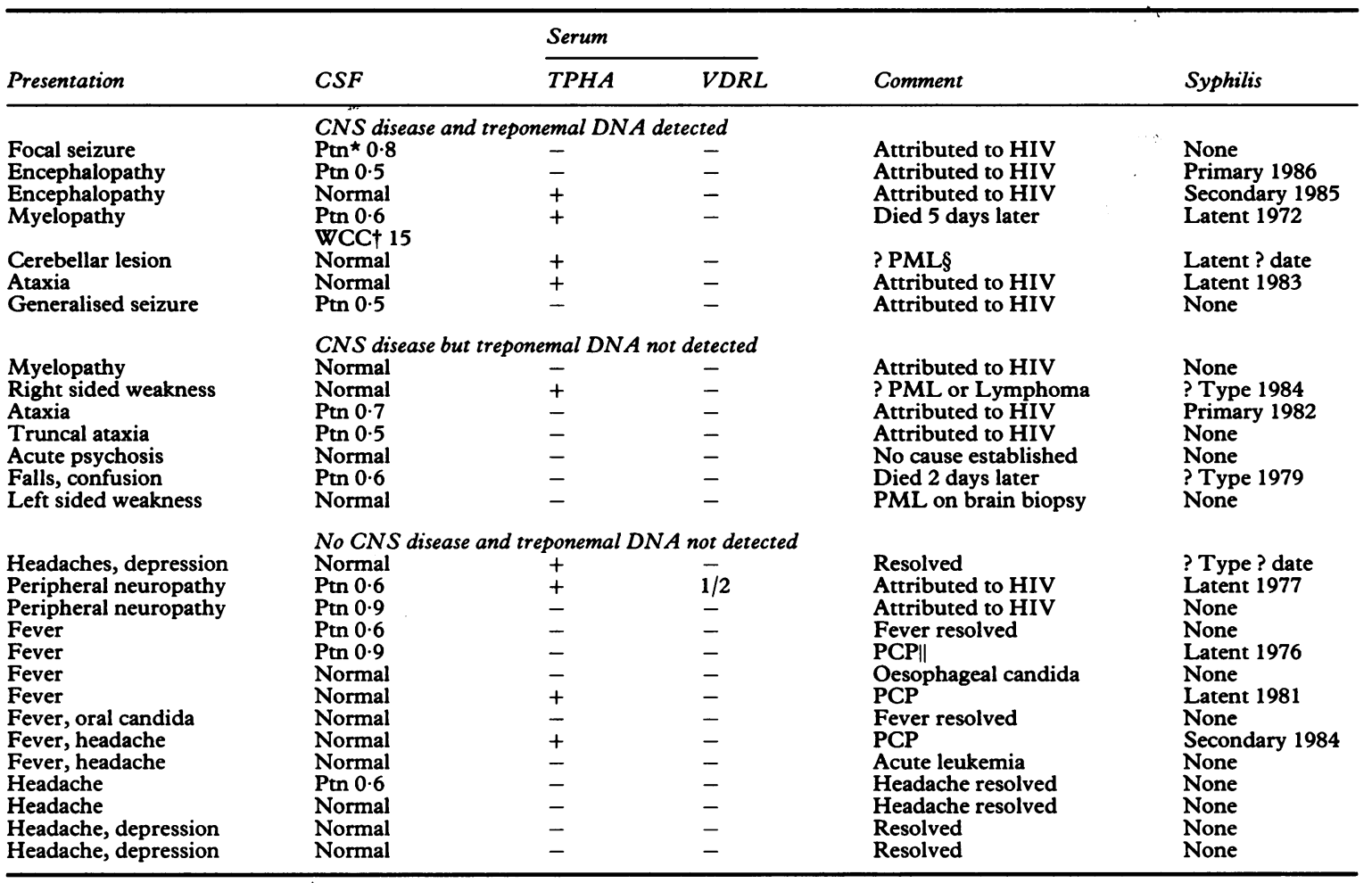

$\star$ Ptn : protein concentration $(\mathbf{g} / \mathbf{l})$

+WCC : white cell count $\left(/ \mathrm{mm}^{3}\right)$

§ML : progressive multifocal leucoencephalopathy

॥PCP : Pneumocystis carinii pneumonia

\section{Group C patients}

Details of these patients and the results of their investigations are shown in tables 2 and 3. There were 14 patients with CNS disease, of whom seven were treponemal DNA positive. In contrast, of 14 patients without $\mathrm{CNS}$ disease, none were treponemal DNA positive (Fishers exact test $p<0.005$ ). Furthermore, five of eight patients who had a history of syphilis and current CNS disease were treponemal DNA positive, while the five patients with a history of syphilis but without CNS disease were all treponemal DNA negative (Fishers exact test $p<0.05$ ).
Four patients gave a history of syphilis but had negative FTA, TPHA and VDRL tests of the serum. One of these patients had been treated for primary syphilis with benzathine penicillin 3 years earlier and was treponemal DNA positive. Another of the four had been treated abroad and it was not possible to confirm the prior diagnosis of syphilis, but he gave a good description of a chancre and treatment with daily injections of penicillin for 15 days. There were two men who did not give a history of syphilis and who had negative serological tests for it, in whom treponemal DNA was detected. These two men had

Table 3 Summary of results for history of syphilis and detection of treponemal DNA in CSF

\begin{tabular}{|c|c|c|c|c|}
\hline \multirow[b]{3}{*}{ Treponemal $D N A$} & \multicolumn{2}{|c|}{ Patients in groups $A / B$} & \multicolumn{2}{|c|}{ Patients in group $C$} \\
\hline & \multicolumn{2}{|l|}{ Syphilis } & \multicolumn{2}{|l|}{ Syphilis } \\
\hline & Untreated & None known & Treated & None known \\
\hline $\begin{array}{l}\text { Positive } \\
\text { Negative }\end{array}$ & $\begin{array}{c}10 \\
7^{\star}\end{array}$ & $\begin{array}{r}1 \\
29\end{array}$ & $\begin{array}{l}5 \\
8\end{array}$ & $\begin{array}{r}2 \\
13\end{array}$ \\
\hline
\end{tabular}

*Two patients previously treated for syphilis who were treponemal DNA negative have been excluded from this table.

It is possible that 1 treponemal DNA negative patient had yaws rather than syphilis. 
had many casual homosexual partners and had been treated on several occasions for gonorrhoea and nongonococcal urethritis with antibiotics which are active against $T$. pallidum.

\section{Discussion}

In total, the CSF from 77 patients in groups $\mathrm{A}, \mathrm{B}$ and $\mathrm{C}$ were tested. Fifteen of 26 patients with a history of syphilis were treponemal DNA-positive compared to 3 of 45 patients without a history of syphilis. Treponemal DNA was detected in CSF from 10 of 17 patients with untreated syphilis in group B (two patients had been treated but were being reevaluated), and in CSF from one of 30 patients not known to have syphilis in group A. Thus, detection of treponemal DNA had a sensitivity of $59 \%$, a specificity of $97 \%$, a positive predictive value (PPV) of $91 \%$, and a negative predictive value (NPV) of $83 \%$ in patients not previously treated for syphilis. In group $\mathrm{C}$ all the patients were HIV-positive and those known to have syphilis had all been treated. Nevertheless, treponemal DNA was detected in five of 13 patients with a history of syphilis, giving a sensitivity of $38 \%$, a specificity of $87 \%$, a PPV of $87 \%$, and a NPV of $62 \%$ for predicting a history of syphilis.

We estimated that DNA equivalent to no less than 65 organisms in $0.5 \mathrm{ml}$ of CSF could be detected by the PCR, which could account for the relatively low sensitivity of the procedure in tests on clinical specimens. However, since this figure was based on multiple dilutions it is possible that the sensitivity is greater than we have estimated. We detected treponemal DNA in the CSF from more than half of the patients with a history of untreated latent syphilis. Previous attempts to detect treponemes in the CSF from patients with late latent syphilis by animal inoculation have failed ${ }^{10}$. or have been successful in only a small proportion of patients. ${ }^{16}$ Our failure to detect treponemal DNA in specimens from more than $40 \%$ of patients with late latent syphilis may be because in a proportion of the patients the infection had been eliminated with or without the assistance of antibiotics prescribed for other conditions. The organisms may not be freely present in CSF, but exist possibly in other tissues or even intracellularly. ${ }^{17}$ Our method does not distinguish between live and dead organisms. It is possible that the differences between our results and those obtained with rabbit inoculation are because the PCR is able to detect non-viable organisms.

The specificity of the PCR was not $100 \%$ because CSF from three patients without a history of syphilis reacted positively in the test. Two of these patients were HIV antibody-positive and had negative serological tests for syphilis. It is possible that they had incubating or early syphilis that had been treated fortuitously, resulting in the inability to detect treponemal or reaginic antibody subsequently. Alternatively, they may have failed to produce antibodies as a consequence of their HIV infection. ${ }^{3}$ Although these two positive results could represent true false positive ones, the overall specificity of the PCR procedure would suggest otherwise. The third patient was in group $A$ and the result must be assumed to be a genuine false positive. Since this work was completed the PCR technique has been modified with the addition of a second amplification cycle for the $4 \mathrm{D}$ gene using internal primers ("nested" PCR). Initial results suggest that this provides increased sensitivity and specificity. Although it has not been possible to retest all the samples with this modification, the CSF from the patient in group A that was positive has been retested on three occasions and has been negative each time, while the fluids from the two patients in group $C$ with no prior history of syphilis have been confirmed positive. The initial result for all the other samples that have been retested has been confirmed. While this points to a high specificity of the original tests it also indicates that the probes and primers used initially were not $100 \%$ specific and, furthermore, suggests that contamination is not the explanation for these three "false-positives".

In this study CNS disease and a history of syphilis predicted the finding of treponemal DNA in the CSF of patients with HIV infection. Immune deficiency is associated with proliferation of $T$. pallidum in the rabbit model, ${ }^{518}$ and it is possible that the patients with CNS disease were more immunocompromised than the others. Whether the detection of treponemal DNA means that treponemes contribute actively to the CNS pathology or merely replicate benignly is open to conjecture. None of the patients exhibited signs such as abnormal pupils that are commonly found in patients with parenchymatous neurosyphilis. Given the sensitivity of treponemes to a rise in temperature it is possible that an intercurrent pyrexial illness in an HIV-positive individual might affect the availability of treponemal DNA in the CSF. A review of the literature has not revealed any reports of treponemes being detected in the brains of patients dying from AIDS with neurological disease. However, only small numbers of treponemes might be needed to cause neurological disease through hypersensitivity or toxic mechanisms, and the techniques used for detecting them may not have been sufficiently sensitive.

The results we have recorded suggest several further lines of investigation. Clearly, examination of further CSF samples from HIV-positive patients to establish the relationship with treponemal disease is warranted. Furthermore, histological examination of tissue in which treponemal DNA can be detected by the PCR may yield information on how treponemes 
could produce disease in immunosuppressed patients. Ultimately, a clinical study, in which treponemal DNA-positive patients are retreated for syphilis with a high dose penicillin regime will show whether our findings are of clinical importance. The PCR would be useful in monitoring the efficacy of treatment in eliminating treponemes in such a study.

This work was initially supported by the Jefferiss Research Trust. Our thanks to Dr Charles Penn, University of Birmingham, UK for support and providing laboratory organisms.

Address for correspondence: Dr Phillip Hay, The Jefferiss Wing, St Mary's Hospital, London W2 $1 \mathrm{NY}$, UK.

1 Haas JS, Bolan G, Larsen S, Clement M, Moss A. "Seroreversion" of treponemal tests during HIV infection. Abstracts V International Conference on AIDS, Montreal, 1989; WBP 54:p 360.

2 Radolf JD, Kaplan RP. Unusual manifestations of secondary syphilis and abnormal humoral immune response to Treponema pallidum antigens in a homosexual man with asymptomatic human immunodeficiency virus infection. J Am Acad Dermatol 1988;18:423-8.

3 Hicks CB, Benson P, Lupton GP, Tramont EC. Seronegative secondary syphilis in a patient infected with HIV with Kaposi's sarcoma. Ann Intern Med 1987;107:492-5.

4 Tramont EC. Persistence of Treponema pallidum following penicillin G therapy. JAMA 1976;236:2206-7.

5 Collart P, Borel LJ, Durel P. Significance of spiral organisms found, after treatment, in late human and experimental syphilis. Br J Venereal Dis 1964;40:81-9.
6 Dunlop EMC. Survival of treponemes after treatment: Comments, clinical conclusions and recommendations. Genitourin Med 1985;61:293-301.

7 Jorgensen J, Tikjob G, Weirmann K. Neurosyphilis after treatment of latent syphilis with benzathine penicillin. Genitourin Med 1986;62:129-31.

8 Rice NSC, Dunlop EMC, Jones BR et al. Treponeme like forms in treated and untreated early syphilis. BrJVenereal Dis 1970;46:1-9.

9 Poitevin M, Collart P, Bolgert M. Syphilis in 1986. J Clin Neuroophthalmol 1987;7:11-6.

10 Lukehart SA, Hook EW, Baker-Zander SA, Collier AL, Critchlow $\mathrm{CW}$, Handsfield $\mathrm{HH}$. Invasion of the central nervous system by Treponema pallidum: implications for diagnosis and treatment. Ann Int Med 1988;109:855-62.

11 Johns DR, Tierney $M$, Felsenstein D. Alteration in the natural history of neurosyphilis by concurrent infection with the human immunodeficiency virus. $N$ Engl J Med 1987;316: 1569-72.

12 Tramont EC. Syphilis in the AIDS era. $N$ Engl J Med 1987; 316:1600-1.

13 Berry CD, Hooton TM, Collier AL, Lukehart SA. Neurologic relapse after benzathine penicillin therapy for secondary syphilis in a patient with HIV infection. N Engl J Med 1987; 316:1587-9.

14 Musher DM. How much penicillin cures early syphilis? Ann Int Med 1988;109:849-51.

15 Hay PE, Clarke JR, Strugnell RA, Taylor-Robinson D, Goldmeier $\mathrm{D}$. Use of the polymerase chain reaction to detect DNA sequences specific to pathogenic treponemes in cerebrospinal fluid. FEMS Microbiol Letters 1990;68:233-8.

16 Turner TB, Hardy PH, Newman B. Infectivity tests in syphilis. Br J Venereal Dis 1969;45:183-5.

17 Ovcinnikov NM, Delektorskij VV. Current concepts of the morphology and biology of Treponema pallidum based on electron microscopy. Br J Venereal Dis 1971;47:315-27.

18 Lukehart SA, Baker-Zander SA, Lloyd RMC, Sell S. Effects of cortisone administration on host-parasite relationships in early experimental syphilis. J Immunol 1981;127:1361-8.

Accepted for publication 11 September 1990 